\title{
Control System Design of Shunt Active Power Filter Based on Active Disturbance Rejection and Repetitive Control Techniques
}

\author{
Le Ge, ${ }^{1,2}$ Xiaodong Yuan, ${ }^{3}$ and Zhong Yang ${ }^{1}$ \\ ${ }^{1}$ College of Automation Engineering, Nanjing University of Aeronautics and Astronautics, Nanjing 210016, China \\ ${ }^{2}$ School of Electric Power Engineering, Nanjing Institute of Technology, Nanjing 211167, China \\ ${ }^{3}$ Department of Renewable Energy and Distribution Network Technology, Jiangsu Electric Power Company Research Institute, \\ Nanjing 211103, China
}

Correspondence should be addressed to Le Ge; gele_nit@sina.com

Received 13 December 2013; Accepted 18 February 2014; Published 23 March 2014

Academic Editor: Xiaojie Su

Copyright (C) 2014 Le Ge et al. This is an open access article distributed under the Creative Commons Attribution License, which permits unrestricted use, distribution, and reproduction in any medium, provided the original work is properly cited.

To rely on joint active disturbance rejection control (ADRC) and repetitive control (RC), in this paper, a compound control law for active power filter (APF) current control system is proposed. According to the theory of ADRC, the uncertainties in the model and from the circumstance outside are considered as the unknown disturbance to the system. The extended state observer can evaluate the unknown disturbance. Next, RC is introduced into current loop to improve the steady characteristics. The ADRC is used to get a good dynamic performance, and RC is used to get a good static performance. A good simulation result is got through choosing and changing the parameters, and the feasibility, adaptability, and robustness of the control are testified by this result.

\section{Introduction}

The proliferation of nonlinear loads caused by more and more modem electronic equipments results in deterioration of power quality in power transmission or distribution systems. Harmonic, reactive, negative sequence and flickers are the reasons of various undesirable phenomena in the operation of power system. In order to solve these problems, the concept of active power filter (APF) was presented. Active power filters, which compensate harmonic and reactive current component for the power supplies, can improve the power qualities and enhance the reliabilities and stabilities on power utility [1-3]. In recent 30 years from APF presented, the continual innovation of control strategies mainly impels the APF techniques to be developed rapidly [4-7].

Active disturbance rejection control (ADRC) is a robust control method that is based on extension of the system model with an additional and fictitious state variable, representing everything that the user does not include in the mathematical description of the plant [8-11]. Different from other disturbances and states estimation [12-15], this virtual state (sum of internal and external disturbances, usually denoted as a "total disturbance") is estimated online with a state observer and used in the control signal in order to decouple the system from the actual perturbation acting on the plant. This disturbance rejection feature allows user to treat the considered system with a simpler model, since the negative effects of modeling uncertainty are compensated in real time. As a result, the operator does not need a precise analytical description of the system, as one can assume the unknown parts of dynamics as the internal disturbance in the plant. Robustness and the adaptive ability of this method make it an interesting solution in scenarios where the full knowledge of the system is not available.

Repetitive control is a control method developed by a group of Japanese scholars in 1980s. It is based on the Internal Model Principle and used specifically in dealing with periodic signals, for example, tracking periodic reference or rejecting periodic disturbances. The repetitive control system has been proven to be a very effective and practical method dealing with periodic signals [15-18]. Repetitive control has some similarities with iterative learning control.

This paper addresses the electric current tracking control problem for shunt APF. The control law is joint ADRC and $\mathrm{RC}$ which can deal with the static and dynamic performance. The rest of this paper is organized as follows. In Section 2, 


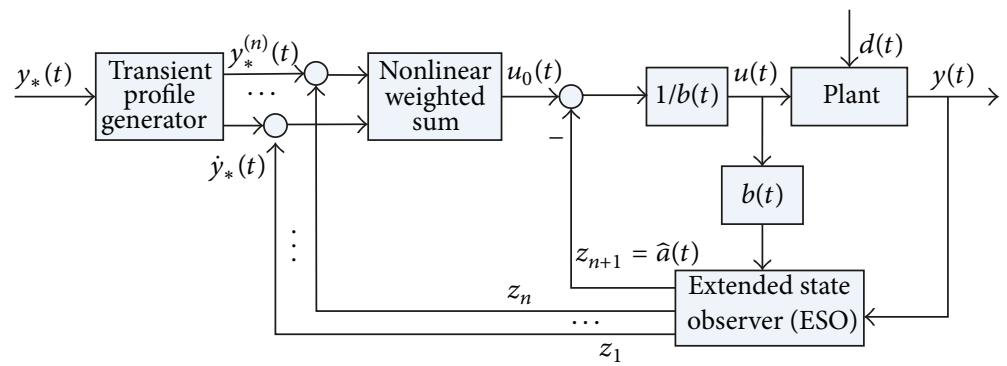

FIGURE 1: Block diagram of the ADRC.

a brief description of the ADRC is presented. In Section 3, main results of $\mathrm{ADRC}+\mathrm{RC}$ control technique are developed. In Section 4, simulation results are presented to show the effectiveness of the proposed control technique. Finally, some conclusions are made in Section 5.

\section{Active Disturbance Rejection Control}

In ADRC, the tracking differentiator (TD) is used to deal with the reference input and the extended state observer (ESO) is used to deal with the output of controlled system. Then the ADRC control law can be selected through the appropriate nonlinear combination of state errors. The general structure of ADRC is shown in Figure 1. In Figure 1 of ADRC, the transient profile generator is used to obtain each order derivative $\dot{y}_{*}(t), \ddot{y}_{*}(t), \ldots, y_{*}^{n}(t)$ of reference trajectory $y_{*}(t)$. Next, brief description of ADRC is given as follows.

Consider a class SISO nonlinear system as

$$
y^{n}=f\left(y, \dot{y}, \ldots, y^{(n-1)}, t\right)+b u(t)+d(t) .
$$

Equation (1) also can be described as

$$
\begin{aligned}
\dot{x}_{1}= & x_{2} \\
& \vdots \\
x_{n-1} & =x_{n} \\
\dot{x}_{n} & =f\left(x_{1}, x_{2}, \ldots, x_{n-1}, t\right)+b u(t)+d(t) \\
y & =x_{1},
\end{aligned}
$$

where $f\left(x_{1}, x_{2}, \ldots, x_{n-1}, t\right)$ is unknown function, $d(t)$ is unknown disturbance, and $u(t)$ is control input.

Construct the following ESO for nonlinear systems (2):

$$
\begin{aligned}
\dot{z}_{1}= & z_{2}-g_{1}\left(z_{1}-y\right) \\
& \vdots \\
\dot{z}_{n}= & z_{n+1}-g_{n}\left(z_{1}-y\right)+b u(t) \\
\dot{z}_{n+1}= & -g_{n+1}\left(z_{1}-y\right) .
\end{aligned}
$$

Let $a(t)=f\left(x_{1}, x_{2}, \ldots, x_{n-1}, t\right)+d(t)$, so we can obtain the following conclusion:

$$
z_{1} \longrightarrow x_{1}, z_{2} \longrightarrow x_{2}, \ldots, z_{n} \longrightarrow x_{n}, z_{n+1} \longrightarrow a
$$

through selecting appropriate nonlinear function $g_{1}, g_{2}, \ldots$, $g_{n+1}$. Defining that $\widehat{a}(t)$ is the estimation value of $a(t)$, we can obtain $z_{n+1}=\widehat{a}(t)$.

From the above brief description of ESO, it can be seen that ESO can be used to estimate the states and the sum of model uncertainty $f\left(x_{1}, x_{2}, \ldots, x_{n-1}, t\right)$ and disturbance $d(t)$. So, ESO is such a link, which uses the output $y(t)$ of plant to get each order derivative signal $z_{1}, z_{2}, \ldots, z_{n}$ and estimation value of disturbance.

Using $z_{1}, z_{2}, \ldots, z_{n}$ from ESO and $\dot{y}_{*}(t), \ddot{y}_{*}(t), \ldots, y_{*}^{n}(t)$ from TD, we get the state errors as

$$
\varepsilon_{i}=y_{*}^{i}(t)-z_{i}, \quad i=1,2, \ldots, n .
$$

So the following nonlinear combination can be gotten by state errors (5):

$$
u_{0}(t)=k_{1} \mathrm{fal}\left(\varepsilon_{1}, \alpha, \delta\right)+\cdots+k_{n} \mathrm{fal}\left(\varepsilon_{n}, \alpha, \delta\right),
$$

where $k_{i}, \alpha$, and $\delta$ are adjustable parameters. And nonlinear function fal is defined as follows:

$$
\operatorname{fal}\left(\varepsilon_{i}, \alpha, \delta\right)= \begin{cases}\left|\varepsilon_{i}\right|^{\alpha} \operatorname{sgn}\left(\varepsilon_{i}\right) & \left|\varepsilon_{i}\right|>\delta \\ \frac{\varepsilon_{i}}{\delta^{1-\alpha}} & \left|\varepsilon_{i}\right| \leq \delta .\end{cases}
$$

Using the nonlinear state errors feedback (6) and estimation value $\widehat{a}(t)$, the ADRC law can be given by

$$
u(t)=\frac{u_{0}(t)-\widehat{a}(t)}{b}, \quad i=1,2, \ldots, n
$$

\section{Main Results}

Shunt APF circuit schematic is shown in Figure 2; the upper and lower arm of the shunt APF can be considered as ideal switch from the APF working principle. The equivalent circuit of APF is shown in Figure 3. Since the switching operation can control voltage size of the AC side. So shunt APF can be considered as a controllable voltage source and a parallel impedance in the circuit, and to compensate harmonic current and reactive current can be achieved.

So we can obtain the model of shunt APF as follows:

$$
L \frac{d i_{c}}{d t}=u_{i}-R i_{c}-u_{c}
$$




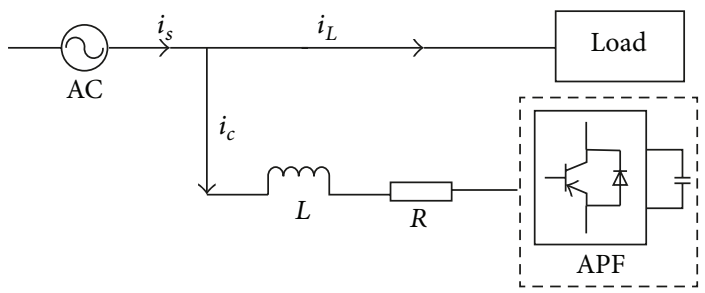

FIGURE 2: Block diagram of shunt APF.

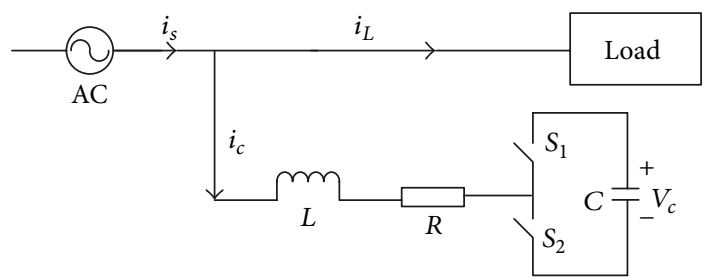

FIGURE 3: Equivalent circuit of shunt APF.

Define PWM as a proportional part, namely, $u_{c}=u V_{c}$, where $u$ is modulation amount. Let $u$ be the control input of system. $V_{c}$ is voltage of DC side. For the supply current, we know

$$
i_{s}=i_{c}+i_{L} .
$$

Substituting (10) into (9), we have

$$
\left(L+L_{s}\right) \frac{d i_{s}}{d t}=-\left(R+R_{s}\right) i_{s}-u V_{c}+u_{s}+R i_{L}+L \frac{d i_{L}}{d t} .
$$

Designed system controller can be considered by a DC voltage outer-loop control and an inner-loop current control. Since the response speed of inner-loop is much faster than the DC voltage outer-loop, it can be considered that DC voltage is constant when the inner current controls. Ignore the impedance of the power line; we let $\bar{d}(t)=u_{s}+R i_{L}+$ $L\left(d i_{L} / d t\right)$; system (11) can be written as

$$
\left(L+L_{s}\right) \frac{d i_{s}}{d t}=-\left(R+R_{s}\right) i_{s}-u V_{c}+\bar{d}(t) .
$$

The APF is a first-order system. ADRC does not need to detect the load current and supply voltage and only uses them as unknown disturbances. A PI controller is used to control the outer-loop DC voltage, which is order to obtain a given current value $i_{s}^{*}(t) . i_{s}^{*}(t)$ can be seen as the reference input $y_{*}(t)$ of ADRC. The control objective is to make the supply current $i_{s}$ able to track the given current value $i_{s}^{*}(t)$ through controlling the modulation amount $u$ of PWM. Set an order TD output as

$$
\dot{z}_{1,1}=-k_{0} \mathrm{fal}\left(\left(z_{1,1}-i_{s}^{*}(t)\right), \alpha_{0}, \delta_{0}\right),
$$

where $k_{0}, \alpha_{0}$, and $\delta_{0}$ are selected parameters. Construct of the following formula ESO:

$$
\begin{aligned}
& \dot{z}_{1}=z_{2}-k_{11} \mathrm{fal}\left(\left(z_{1}-i_{s}^{*}(t)\right), \alpha_{1}, \delta_{1}\right)-V_{c} u(t), \\
& \dot{z}_{2}=-k_{12} \mathrm{fal}\left(\left(z_{1}-i_{s}^{*}(t)\right), \alpha_{1}, \delta_{1}\right),
\end{aligned}
$$

where $k_{11}, k_{12}, \alpha_{1}$, and $\delta_{1}$ are selected parameters. So we can obtain the ADRC law as

$$
\begin{gathered}
u_{0}(t)=k_{2} \operatorname{fal}\left(\left(i_{s}^{*}(t)-z_{1}\right), \alpha_{2}, \delta_{2}\right), \\
u(t)=\frac{u_{0}(t)-\dot{z}_{2}}{V_{c}},
\end{gathered}
$$

where $k_{2}, \alpha_{2}$, and $\delta_{2}$ are also selected parameters. All selected parameters of ADRC controller must try to get in simulation.

$\mathrm{RC}$ is mainly used in continuous processes for tracking or rejecting periodic exogenous signals. In most cases, the period of the exogenous signal is known. The internal model principle is the theoretical foundation of RC. According to internal model principle, to track or reject a certain signal without steady-state error, the signal can be regarded as the output of an autonomous generator that is inside the control system.

Although RC system can still get a good static performance, it cannot get a good dynamic performance of the system. RC is usually used to meet up with other control strategies. Actually, RC is only used to restrain the tracking error. But ADRC can improve the rapid response of the system. After being coupled with the repetitive controller, controller can detect the tracking error and accumulate a correction on the basis of the original command to reduce the error. Repetitive controller can be seen as an embedded component, so this system is called embedded repetitive control system (ERCS). Figure 4 is a block diagram of a parallel ADRC with RC. Next, how to select the controller parameters of RC is shown as follows.

(1) Cycle delay factor $N: N$ is sampled beat number of sinusoidal cycle and can be described as fundamental frequency $f_{s}$ and the switching frequency $f_{c}$.

(2) Compensation link $Q(z): Q(z)$ characterizes the steady precision of repetitive controller. In general, $Q(z)$ is a constant. When $Q(z)=1$, the open-loop gain of system is infinite, and steady-state error is zero. But this may likely cause system instability. So we usually select a constant that is less than but close to $1 . Q(z)$ is also preferably chosen zero phase low pass filter.

(3) Compensation link $S(z)$ of plant: $S(z)$ is used to reform the controlled plant. After reformation, the amplitude-frequency characteristics of the plant has zero gain in the low frequency band. Generally, the series correction part $S_{1}(z)$ is first selected to correct the low-frequency gain of controlled plant. Then, in order to improve system stability, the second-order low-pass filter is selected to attenuate high frequency gain.

(4) Phase compensation factor $k$ : the aim of phase compensation factor $k$ is to compensate phase lag for reformed controlled plant in the low frequency.

(5) Repetitive controller gain $K_{r}: K_{r}$ is used to ensure the stability of the system in the high frequency band. The smaller $K_{r}$ can cause the better stability, but the speed of convergence will become slow and the steady-state 


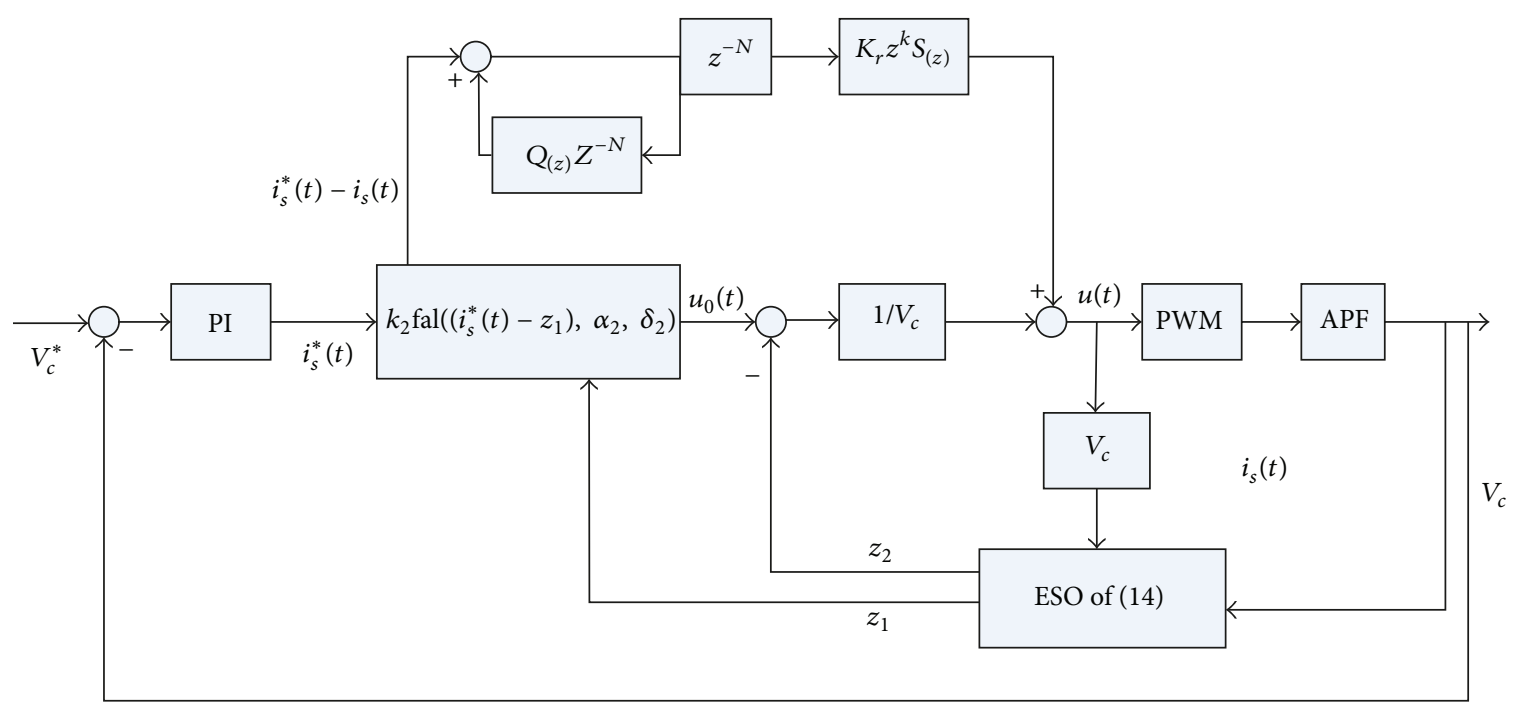

FIGURE 4: Block diagram of a parallel ADRC with RC for shunt APF.

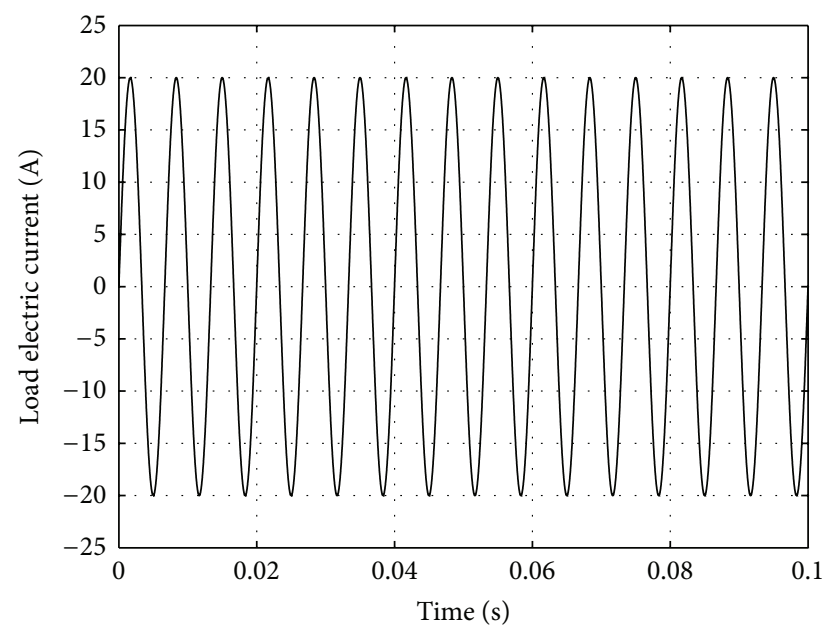

FIgURE 5: Load electric current.

error will increase. In general, $K_{r}$ is chosen to be close to 1 as possible under maintaining the well stability of the RC.

\section{Simulation Results}

In this section, we use Matlab/Simulink for testing and verifying the proposed APF control method. The parameters of chosen APF are $L=1 \mathrm{H}, R=8 \Omega, T=100 \mu \mathrm{s}$, and $f_{c}=10 \mathrm{kHz}$. The ADRC controller parameters are designed as $\alpha_{0}=2, \alpha_{1}=0.5, \alpha_{0}=1, \delta_{0}=0.00001, \delta_{1}=0.001$, $\delta_{0}=0.00001, k_{0}=8000, k_{11}=10000, k_{12}=50000$, and $k_{2}=500$. The RC controller parameters are designed as $N=$ $200, S_{1}(z)=(z-0995) /[0.1248(z-06)], S_{2}(z)=\left(0.0675 z^{2}+\right.$ $01349 z+00675) /\left(z^{2}-1143 z+0.4128\right), Q(z)=0.97, k=3$, and $K_{r}=0.8$. First, we consider the $150 \mathrm{~Hz}$ sine wave for load. Figures 5 and 6 show the load electric current which is third harmonic and the output current $i(t)$ of controlled APF.

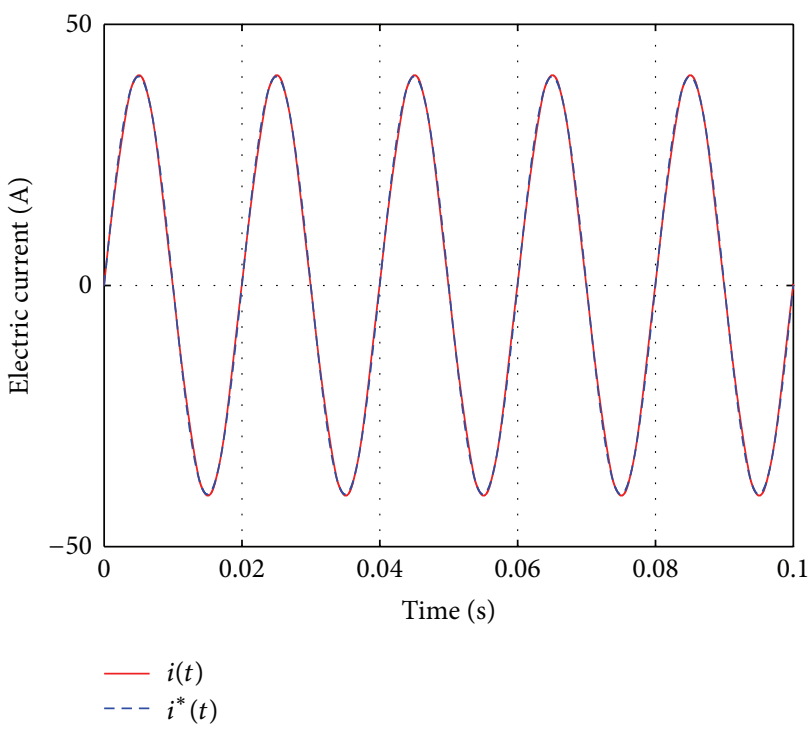

FIGURE 6: Reference current $i^{*}(t)$ and output current $i(t)$ of controlled APF.

Figure 7 shows the total harmonic distortion (THD) analysis for grid current. It can be seen that the proposed control method of the APF can better restrain harmonic of grid. The value of TDH can achieve $0.26 \%$.

First, we consider the $200 \mathrm{~Hz}$ square wave signal for load. Figures 8 and 9 show the load electric current which is fourth harmonic and the output current $i(t)$ of controlled APF. Figure 10 shows the total harmonic distortion (THD) analysis for grid current. It can be seen that the proposed control method of the APF can better restrain harmonic of grid. The value of TDH can achieve $3.88 \%$.

In simulation process, we do not correct the controller parameters, just change the distortion form of load; the simulation results are provided to show that the proposed 


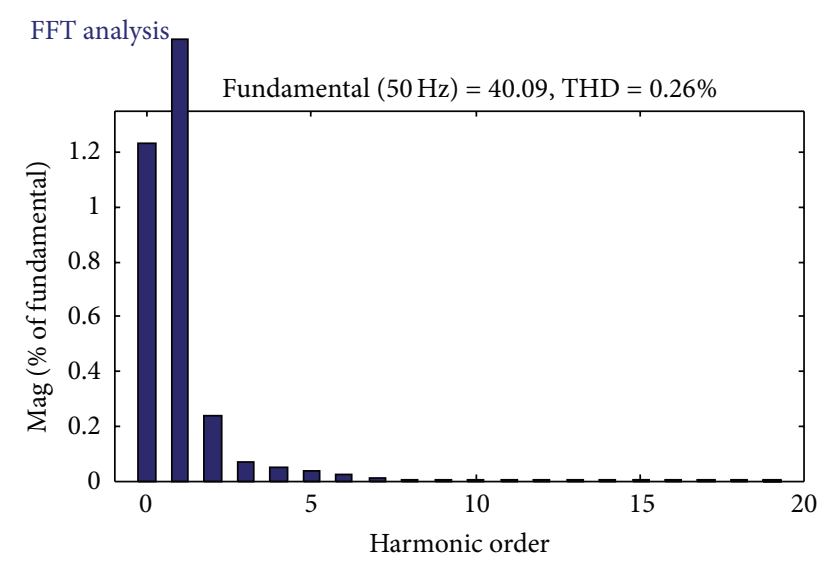

FIGURE 7: THD analysis for grid current.

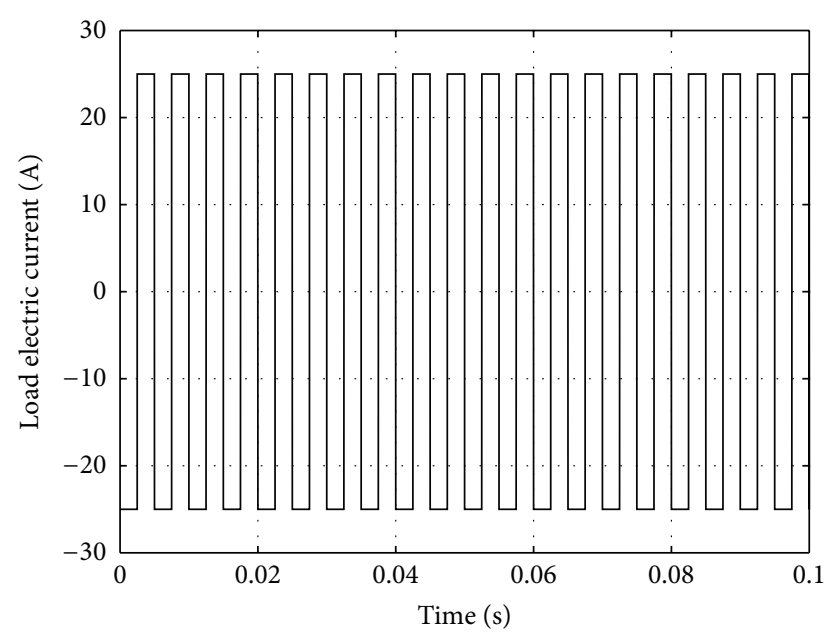

FIgURE 8: Load electric current.

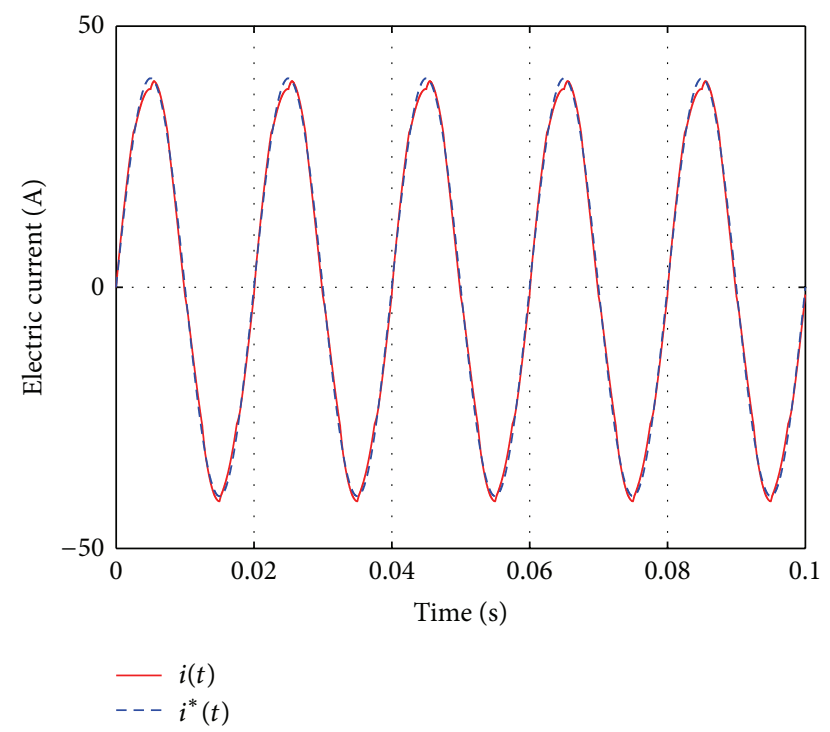

FIgURE 9: Reference current $i^{*}(t)$ and output current $i(t)$ of controlled APF.

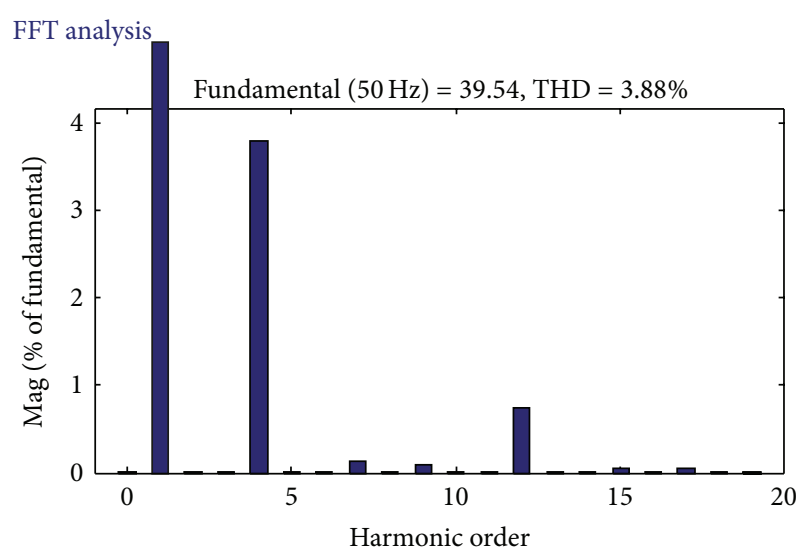

FiguRE 10: THD analysis for grid current.

control algorithm of APF has a very reliable robustness and adaptability for the different distortion forms.

\section{Conclusions}

Since the switch voltage drops, the drive circuit delay differs and dead zones are affected, there are a large number of low-order harmonics in the output current of a single-phase grid-connected APF. The traditional PI controller exists the capacity deficiencies in the harmonic suppression, and unable realizes the static error tracking for the sine command current. It can effectively improve the grid current waveform through ADRC + RC controller. In this paper, we give the composite control law design method for single-phase grid connected APF current loop. Theory and simulation are provided to show that the proposed control algorithm has a very reliable tracking ability and satisfactory robustness to different harmonics of the load.

\section{Conflict of Interests}

The authors declare that there is no conflict of interests regarding the publication of this paper.

\section{Acknowledgments}

The authors wish to thank Professor Yongqiang Ye and Dr. Xu for their constructive comments and suggestions which have helped to improve the presentation of the paper. This work was partially supported by the Advanced Research Project of Jiangsu Electric Power Company Research Institute.

\section{References}

[1] T.-F. Wu, H.-S. Nien, H.-M. Hsieh, and C.-L. Shen, "PV power injection and active power filtering with amplitudeclamping and amplitude-scaling algorithms," IEEE Transactions on Industry Applications, vol. 43, no. 3, pp. 731-741, 2007.

[2] G. Zhang, T. Zhang, M. Ding, J. Su, and H. Wang, "Combined control of active power filter and PV grid connected generation," Automation of Electric Power Systems, vol. 31, no. 8, pp. 61-66, 2007. 
[3] H. Akagi, "New trends in active filters for power conditioning," IEEE Transactions on Industry Applications, vol. 32, no. 6, pp. 1312-1322, 1996.

[4] V. B. Sriram, S. SenGupta, and A. Patra, "Indirect current control of a single-phase voltage-sourced boost-type bridge converter operated in the rectifier mode," IEEE Transactions on Power Electronics, vol. 18, no. 5, pp. 1130-1137, 2003.

[5] H. Akagi, A. Nabae, and S. Atoh, "Control strategy of active power filters using multiple voltage-source PWM converters," IEEE Transactions on Industry Applications, vol. 22, no. 3, pp. 460-465, 1986.

[6] L. Malesani and P. Tenti, "Novel hysteresis control method for current-controlled voltage-source PWM inverters with constant modulation frequency," IEEE Transactions on Industry Applications, vol. 26, no. 1, pp. 88-92, 1990.

[7] M. I. M. Montero, E. R. Cadaval, and F. B. González, "Comparison of control strategies for shunt active power filters in three-phase four-wire systems," IEEE Transactions on Power Electronics, vol. 22, no. 1, pp. 229-236, 2007.

[8] Z. Gao, "Active disturbance rejection control: a paradigm shift in feedback control system design," in Proceedings of the American Control Conference, pp. 2399-2405, June 2006.

[9] J. Han, "Active disturbances rejection control technique," Frontier Scientific, vol. 1, no. 1, article 24C31, 2007.

[10] J. Han, "From PID to active disturbance rejection control," IEEE Transactions on Industrial Electronics, vol. 56, no. 3, pp. 900906, 2009.

[11] B. Sun and Z. Gao, "A DSP-based active disturbance rejection control design for a 1-kW H-bridge DC-DC power converter," IEEE Transactions on Industrial Electronics, vol. 52, no. 5, pp. 1271-1277, 2005.

[12] X. Su, L. Wu, and P. Shi, "Senor networks with random link failures: distributed filtering for T-S fuzzy systems," IEEE Transactions on Industrial Informatics, vol. 9, no. 3, pp. 17391750, 2013.

[13] E. Ikonen, J. Kovacs, and J. Ritvanen, "Circulating fluidized bed hot-loop analysis, tuning, and stateestimation using particle filtering," International Journal of Innovative Computing, Information and Control, vol. 9, no. 8, pp. 3357-3376, 2013.

[14] C. Ahn and P. Kim, "New energy-to-peak FIR filter design for systems with disturbance: a convex optimization approach," International Journal of Innovative Computing, Information and Control, vol. 9, no. 5, pp. 1987-1993, 2013.

[15] X. Su, P. Shi, L. Wu, and S. K. Nguang, "Induced $l_{2}$ filtering of fuzzy stochastic systems with time-varying delays," IEEE Transactions on Cybernetics, vol. 43, no. 4, pp. 1251-1264, 2013.

[16] I. Murakami, T. Sakanushi, K. Yamada, Y. Ando, T. Hagiwara, and S. Matsuura, "The parameterization of all stabilizing simple repetitive controllers with the specified input-output characteristic," ICIC Express Letters, vol. 4, no. 5 B, pp. 1773-1778, 2010.

[17] T. Sakanushi, K. Yamada, I. Murakami et al., "A design method for simple repetitive controllers with specified input-output characteristic," International Journal of Innovative Computing, Information and Control, vol. 8, no. 7, pp. 4883-4899, 2012.

[18] S. Hara, Y. Yamamoto, T. Omata, and M. Nakano, "Repetitive control system: a new type of servo system for periodic exogenous signals," IEEE Transactions on Automatic Control, vol. 33, no. 7, pp. 659-668, 1988. 


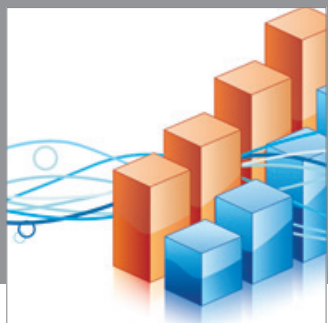

Advances in

Operations Research

mansans

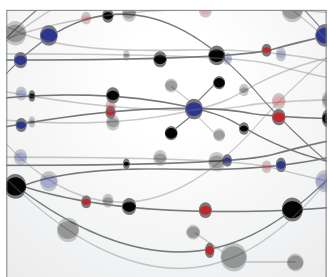

The Scientific World Journal
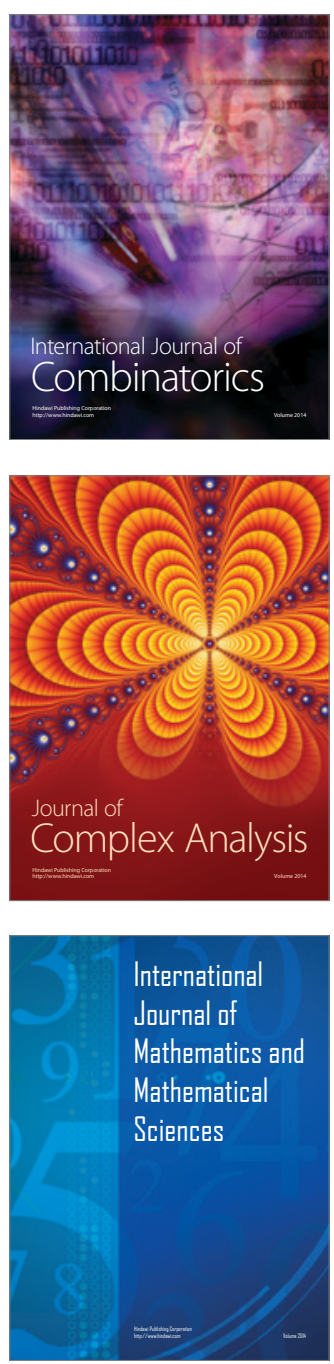
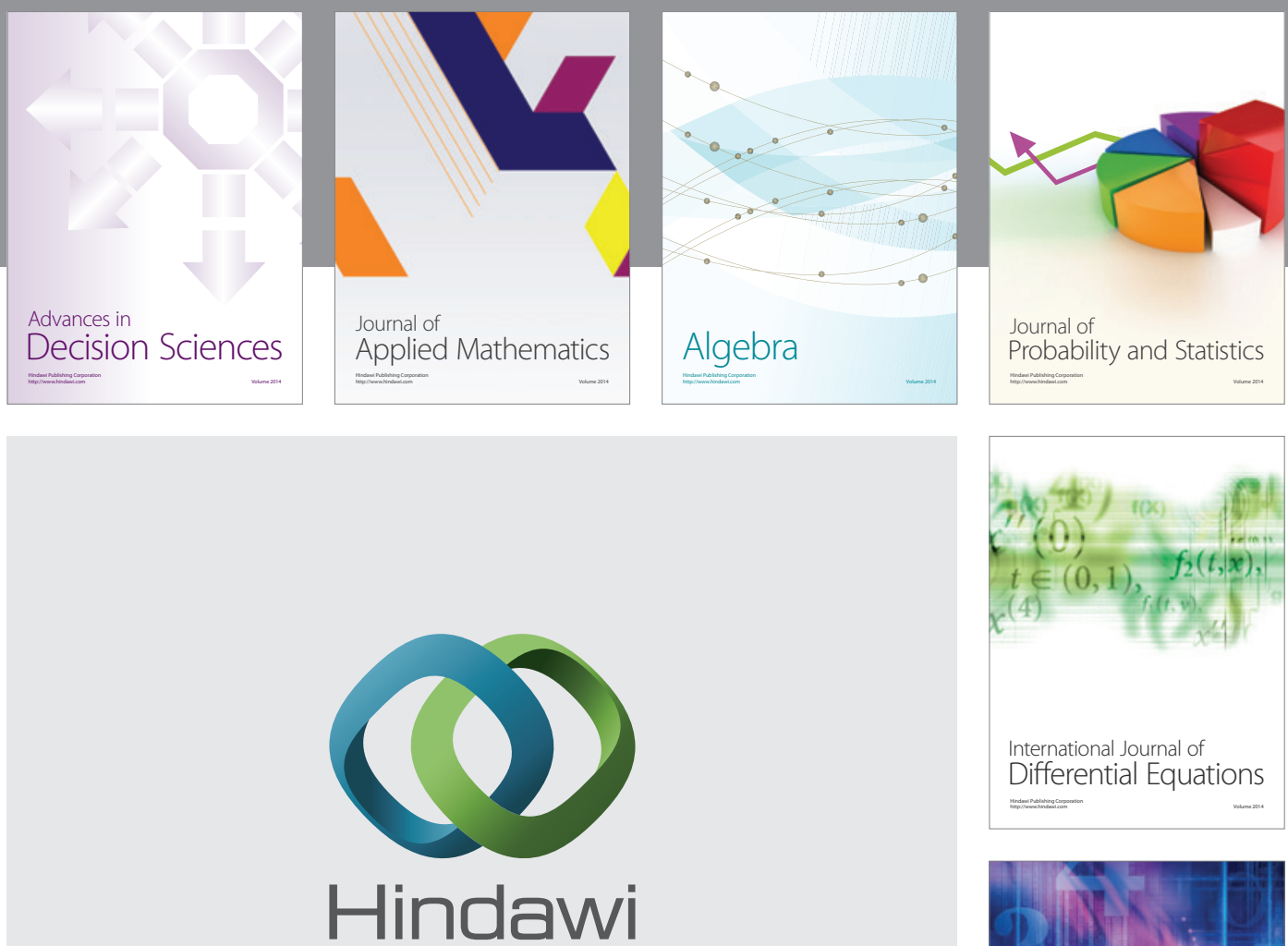

Submit your manuscripts at http://www.hindawi.com
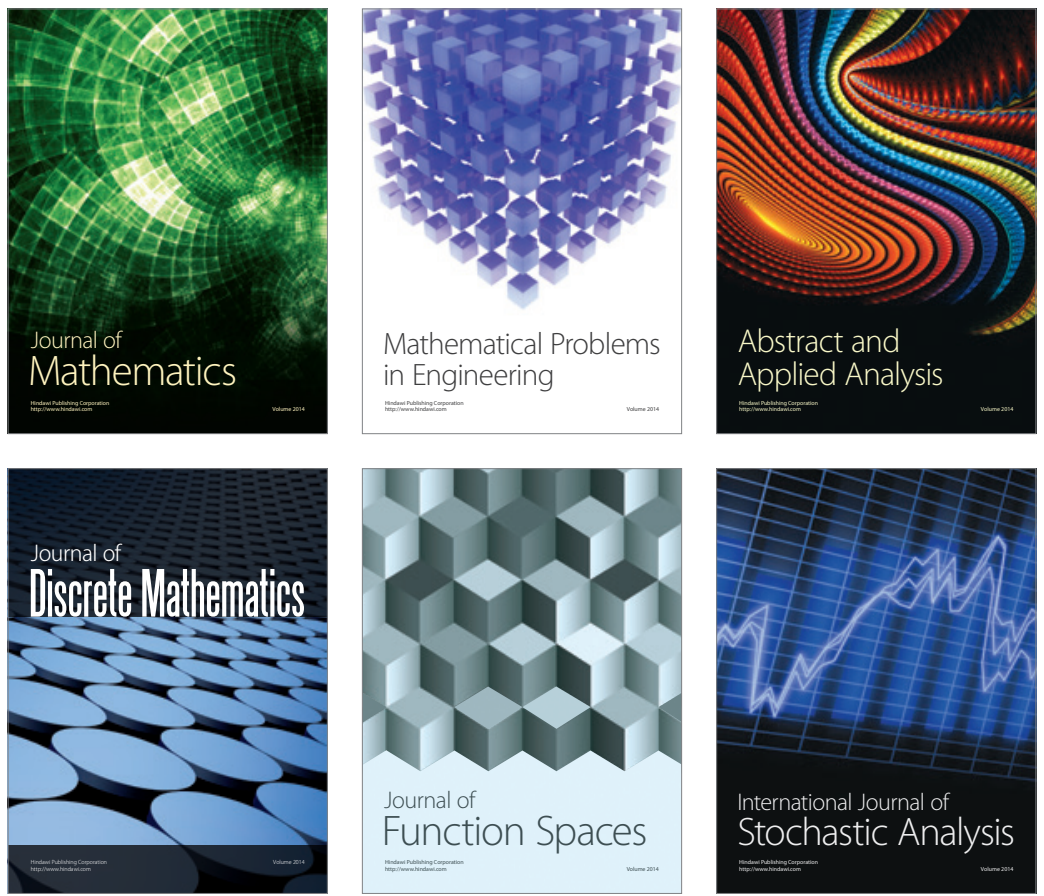

Journal of

Function Spaces

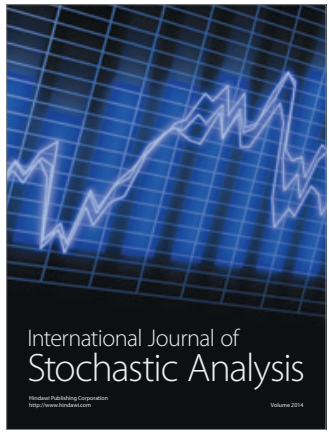

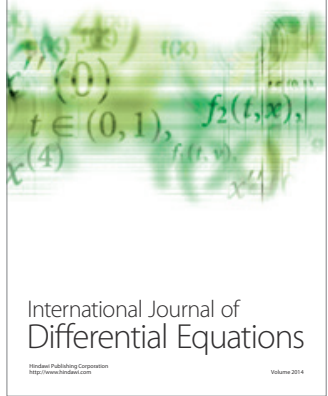
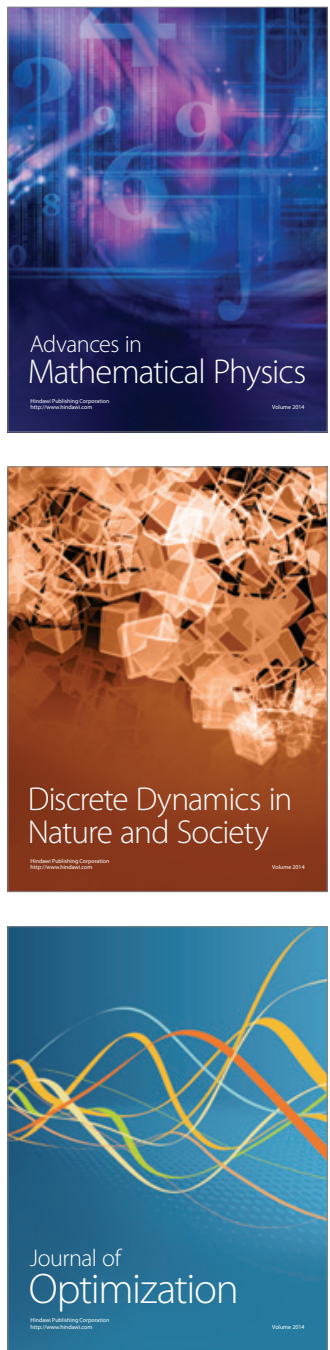